\title{
Beyond Water Stress: Structural Adjustment and Macroeconomic Consequences of the Emerging Water Scarcity
}

\author{
Roberto Roson \\ Ca' Foscari University, Venice and IEFE, Bocconi University, Milan \\ Richard Damania \\ The World Bank, Washington D.C.
}

April 24, 2017

\begin{abstract}
TBW

Keywords:

Water, Economic Growth, Shared Socio-economic Pathways, Computable General Equilibrium, Virtual Water Trade.
\end{abstract}

JEL Codes: C68, F18, F43, O11, Q01, Q25, Q32, Q56. 


\section{Introduction}

TBW

\section{The design of a set of simulation exercises}

We base our modeling exercise on the Shared Socio-Economic Scenario 1 (SSP1), referred to the year 2050 (Kriegler et al., 2012; O’Neill et al., 2014), for projections of GDP and population. SSP1 is characterized by the following narrative: "Sustainable development proceeds at a reasonably high pace, inequalities are lessened, technological change is rapid and directed toward environmentally friendly processes, including lower carbon energy sources and high productivity of land”.

As in Roson (2016) and Roson and Damania (2016) CGE simulations are conducted to extrapolate the potential water demand, consistent with the economic growth hypotheses of SSP1, as well as to assess the amount of future water deficits (excess demand for water), occurring at a given year. The whole process is described in more detail in the Appendix A.

Our global model considers 14 macro-regions, and we found that potential water demand would exceed "sustainable" levels of aggregate consumption in four of them: Middle East and North Africa (MENA), Central (C_Asia), East (E_Asia) and South Asia (S_Asia), at varying degrees, as shown in Table 1.

Table 1

Percentage of potential water demand

exceeding sustainable supply

\begin{tabular}{|l|r|}
\hline & SSP1-2050 \\
\hline MENA & -77.1 \\
\hline C_Asia & -4.4 \\
\hline E_Asia & -42.9 \\
\hline S_Asia & -50.2 \\
\hline
\end{tabular}

If water availability will become a hard constraint for the regional economies, scenarios of economic growth (which is especially sustained in the SSP1), and their associated potential water demand, will turn out to be incompatible with the actual availability of resources, meaning that any excess demand for water must be absorbed by the economic systems, in some way.

Since we are working with very large macro-regions, furthermore considering yearly flow data, we can imagine that efficiency improvements could be achieved by reallocating water consuming activities in time and space within the macro-region and during the year. This would possibly be obtained through the normal market functioning, driven by the changing relative competitiveness of the various 
economic units, induced by water scarcity. In addition, water saving technologies could be introduced, as the corresponding investment would therefore be justified by the rising cost of water.

However, it is extremely difficult to assess the degree of endogenous efficiency gains potentially achievable in the water stressed macro-regions, in this case occurring at the year 2050. To conduct our simulations experiments, we therefore adopt two sets of hypotheses. The first one is a simple benchmark case, consistent with our previous work (Roson and Damania, 2016), were it is assumed that efficiency improvements can cover $75 \%$ of the demand gap in all water stressed regions. The remaining $25 \%$ should therefore be interpreted as cuts in water availability; for instance, the $77.1 \%$ excess demand in the MENA region would bring about a reduction in water availability of 19.27\%. Alternatively, we consider various factors (economic, technical and institutional) that could ultimately affect the actual degree of "flexibility" in the regional economic systems or, in other words, their "absorption capacity” of the excess demand. Appendix C illustrates how a scenario of regionally differentiated impacts was built. In this secondary setting, we assume that the reductions in water availability, expressed as a share of the regional demand gap (which was 25\% in the previous case), are fixed at 26\% for MENA, 34\% for C_Asia, 8\% for E_Asia, 18\% for S_Asia.

The reductions in water availability, determined for the regional aggregate, correspond to reductions imputed at a finer sectoral level. Again, we use here two scenarios. The first one is simplistic: sectoral water availability is reduced proportionally across the board. For example, $-19.27 \%$ water in the MENA region corresponds to $-19.27 \%$ in all water-using sectors inside MENA. The second scenario is a little more elaborated, because sectoral reductions are made sensitive to the relative water efficiency. As in Roson and Damania (2016) sectoral reductions $\left(\rho_{i r}\right)$ are increasing functions of the "water per unit of output", or water intensity, coefficients $\left(\omega_{i r}\right)$ :

$\rho_{i r}=\alpha_{r}+\left(\frac{\omega_{i r}}{\bar{\omega}_{r}}\right)^{0.25}$

where $\alpha_{r}$ is a constant, determined for each region $r$, set at a level ensuring that the sum of all sectoral reductions matches the one imposed to the regional aggregate, and $\bar{\omega}_{r}$ is the average water intensity in the region. Roson and Damania (2016) explain how these water intensity coefficients have been estimated. The inverse of the water intensity can be interpreted as the (average) water productivity. Therefore, (1) establishes that sectoral reductions in water availability are larger for those sectors with lower relative water efficiency, which are typically found in agriculture.

Combining the alternative assumptions, we obtain three scenarios for our numerical simulations:

- No regional differentiation in absorption capacity, uniform reduction of water availability in all sectors [NRUS];

- Regional differentiation in absorption capacity, uniform reduction of water availability in all sectors [DRUS];

- Regional differentiation in absorption capacity, non-uniform (efficiency sensitive) reduction of water availability in the various sectors [DRES].

By selecting one of the three cases above, one implicitly determines how large the cuts in water consumption are expected to be, in each regional sector. 
To gauge the macroeconomic impact of the lower water availability, the latter is translated in terms of changes in (multifactor) industrial productivity. For example, less water in agriculture implies lower yields, ceteris paribus. In this study, the water-induced variation in productivity depends on specific characteristics of the different industries, which are partly captured by a set of "water-output elasticity" parameters. Appendix B illustrates how region and industry specific parameters for the output elasticity and the marginal value of water were estimated. The mean output elasticity is 0.8 . This implies that, on average, a $10 \%$ reduction in water usage entails an $8 \%$ reduction in industrial productivity.

Linking water to productivity allows us to conduct some numerical simulations with the global GTAP CGE model, because productivity parameters are exogenous in the system expressing the equilibrium conditions for the various markets. After changing some productivity factors, then, a new counterfactual equilibrium can be computed, where variations in endogenous macroeconomic variables, like relative prices, trade flows, production volumes and others can be analyzed.

In the following section, some findings corresponding to the three simulation scenarios are presented and discussed. The results are expressed as relative to a hypothetical reference, where the regional economies grow at the rate imposed by the SSP1, but there is no lack of water resources, thus no effects on productivity related to water availability.

\section{Results}

Variations is water availability for each industry in water stressed macro-regions are defined for the three simulation scenarios (NRUS, DRUS, DRES) and transformed as exogenous productivity shocks, to enter the CGE model. For example, Table 2 shows the productivity variations for MENA in the three cases.

Notice that, when water efficiency is considered in the allocation scheme (DRES), a few industries obtain productivity gains. This is because, even if water consumption is reduced in the region as a whole, some individual industries, where relatively little water is used per unit (value) of output, actually get increases in water assignments.

The CGE system computes a global economic equilibrium consistent with the exogenous shocks above, and the model delivers estimates for several macroeconomic variables, like: production volumes, employment, investments, consumption patterns, trade flows, price indexes, GDP deflators, etc. We present here only a limited set of results, to illustrate the key characteristics of the three scenarios. 
Table 2

Industrial productivity shocks in the MENA region

\begin{tabular}{|l|c|c|c|}
\hline & NRUS & DRUS & DRES \\
\hline Rice & $-35.74 \%$ & $-37.17 \%$ & $-70.42 \%$ \\
\hline Wheat & $-24.03 \%$ & $-25.00 \%$ & $-45.26 \%$ \\
\hline Cereals & $-24.27 \%$ & $-25.25 \%$ & $-47.36 \%$ \\
\hline VegFruit & $-30.73 \%$ & $-31.96 \%$ & $-40.63 \%$ \\
\hline Oilseeds & $-21.67 \%$ & $-22.54 \%$ & $-37.89 \%$ \\
\hline Sugar & $-22.34 \%$ & $-23.24 \%$ & $-34.63 \%$ \\
\hline Oth Crops & $-18.06 \%$ & $-18.78 \%$ & $-17.20 \%$ \\
\hline Oth Agr. & $-36.20 \%$ & $-37.65 \%$ & $-35.17 \%$ \\
\hline Extr & $-18.82 \%$ & $-19.57 \%$ & $-13.10 \%$ \\
\hline P.Food & $-14.03 \%$ & $-14.60 \%$ & $5.30 \%$ \\
\hline Textiles & $-17.29 \%$ & $-17.98 \%$ & $7.05 \%$ \\
\hline Light Man & $-23.21 \%$ & $-24.13 \%$ & $9.63 \%$ \\
\hline Heavy Man & $-13.79 \%$ & $-14.35 \%$ & $3.75 \%$ \\
\hline Utilities & $-13.38 \%$ & $-13.91 \%$ & $-7.59 \%$ \\
\hline
\end{tabular}

We start by considering the variations in Real GDP, or national income, relative to the benchmark where water scarcity has no impact on industrial productivity (Table 3).

Table 3

Variations in real GDP

\begin{tabular}{|c|c|c|c|}
\hline & NRUS & DRUS & DRES \\
\hline N_America & $-0.01 \%$ & $-0.01 \%$ & $0.00 \%$ \\
\hline C_America & $0.05 \%$ & $0.05 \%$ & $0.06 \%$ \\
\hline S_America & $-0.01 \%$ & $0.00 \%$ & $0.01 \%$ \\
\hline W_Europe & $0.00 \%$ & $0.00 \%$ & $-0.01 \%$ \\
\hline E_Europe & $-0.04 \%$ & $-0.03 \%$ & $-0.05 \%$ \\
\hline MENA & $-8.64 \%$ & $-8.99 \%$ & $-3.77 \%$ \\
\hline Sahel & $0.21 \%$ & $0.28 \%$ & $0.51 \%$ \\
\hline C_Africa & $0.26 \%$ & $0.27 \%$ & $0.29 \%$ \\
\hline S_Africa & $-0.02 \%$ & $0.00 \%$ & $0.05 \%$ \\
\hline C_Asia & $-0.38 \%$ & $-0.57 \%$ & $0.42 \%$ \\
\hline E_Asia & $-2.47 \%$ & $-0.80 \%$ & $0.42 \%$ \\
\hline S_Asia & $-4.17 \%$ & $-3.36 \%$ & $0.44 \%$ \\
\hline SE_Asia & $-0.03 \%$ & $0.00 \%$ & $0.01 \%$ \\
\hline Australasia & $-0.02 \%$ & $-0.01 \%$ & $0.01 \%$ \\
\hline
\end{tabular}

Drops in (potential) GDP are quite substantial in water stressed macro-regions, most notably in the Middle East and North Africa (MENA). When differences in absorption capacities are taken into 
account, the picture changes significantly for East Asia (dominated by China), because we are assuming that as much as $92 \%$ of the water deficit can be accommodated there, through endogenous efficiency gains and technological progress.

Results for the DRES scenario indicate that the economic impact of water scarcity can be greatly contained when the economic returns per unit of water are considered in the industrial rationing scheme. Interestingly, the negative shock turns positive in the Asian regions, where the aggregate efficiency gains of a better inter-industrial allocation of water resources overrules the direct productivity effect.

To appreciate the impacts on the welfare of households, we employ the Equivalent Variation (EV) concept. The EV is the welfare equivalent reduction in income, virtually obtainable at unchanged relative prices. Therefore, it is the welfare "cost" of an exogenous shock or policy. Table 4 expresses the EV as relative to the benchmark GDP level.

Table 4

$E V / G D P$

\begin{tabular}{|l|r|r|r|}
\hline & \multicolumn{1}{|c|}{ NRUS } & \multicolumn{1}{c|}{ DRUS } & \multicolumn{1}{c|}{ DRES } \\
\hline N_America & $-0.03 \%$ & $-0.02 \%$ & $0.00 \%$ \\
\hline C_America & $0.01 \%$ & $0.02 \%$ & $0.02 \%$ \\
\hline S_America & $0.01 \%$ & $0.01 \%$ & $0.02 \%$ \\
\hline W_Europe & $-0.03 \%$ & $-0.02 \%$ & $-0.01 \%$ \\
\hline E_Europe & $0.01 \%$ & $0.01 \%$ & $0.01 \%$ \\
\hline MENA & $-1.18 \%$ & $-1.23 \%$ & $-0.43 \%$ \\
\hline Sahel & $0.07 \%$ & $0.08 \%$ & $0.10 \%$ \\
\hline C_Africa & $0.16 \%$ & $0.15 \%$ & $0.14 \%$ \\
\hline S_Africa & $0.02 \%$ & $0.02 \%$ & $0.03 \%$ \\
\hline C_Asia & $0.09 \%$ & $0.07 \%$ & $0.14 \%$ \\
\hline E_Asia & $-0.14 \%$ & $-0.05 \%$ & $0.01 \%$ \\
\hline S_Asia & $-0.25 \%$ & $-0.21 \%$ & $0.04 \%$ \\
\hline SE_Asia & $0.02 \%$ & $0.02 \%$ & $0.02 \%$ \\
\hline Australasia & $0.00 \%$ & $0.00 \%$ & $0.00 \%$ \\
\hline
\end{tabular}

Table 4 closely mirrors Table 3, but with much smaller figures in absolute value. The reason is that water scarcity affects regions and industries in a differentiated way, so that the representative regional consumer can substitute water-intensive and relatively more expensive goods with cheaper ones, possibly imported from abroad. This endogenous substitution mechanism curbs the overall impact on the welfare of consumers.

Correspondingly, the industrial structure changes in the regions where water gets progressively scarcer. By way of illustration, Table 5 presents the changes in industrial output volumes in the MENA region. 
Table 5

Industrial output changes in the MENA region

\begin{tabular}{|l|r|r|r|}
\hline & \multicolumn{1}{|c|}{ NRUS } & \multicolumn{1}{c|}{ DRUS } & \multicolumn{1}{c|}{ DRES } \\
\hline Rice & $-12.83 \%$ & $-13.69 \%$ & $-26.70 \%$ \\
\hline Wheat & $-14.31 \%$ & $-15.20 \%$ & $-31.37 \%$ \\
\hline Cereals & $-9.25 \%$ & $-9.70 \%$ & $-15.03 \%$ \\
\hline VegFruit & $-6.31 \%$ & $-6.67 \%$ & $-8.20 \%$ \\
\hline Oilseeds & $-15.67 \%$ & $-16.61 \%$ & $-33.38 \%$ \\
\hline Sugar & $-6.02 \%$ & $-6.30 \%$ & $-4.45 \%$ \\
\hline Fibers & $-7.95 \%$ & $-8.50 \%$ & $-5.61 \%$ \\
\hline Oth Crops & $-13.32 \%$ & $-14.24 \%$ & $-26.39 \%$ \\
\hline Oth Agr. & $-12.93 \%$ & $-13.80 \%$ & $-13.91 \%$ \\
\hline Extraction & $-18.32 \%$ & $-19.26 \%$ & $-14.40 \%$ \\
\hline P.Food & $-6.96 \%$ & $-7.26 \%$ & $-4.09 \%$ \\
\hline Textiles & $-7.49 \%$ & $-8.39 \%$ & $7.73 \%$ \\
\hline Light Man & $-18.80 \%$ & $-19.90 \%$ & $13.08 \%$ \\
\hline Heavy Man & $-12.22 \%$ & $-12.86 \%$ & $3.66 \%$ \\
\hline Electricity & $-7.96 \%$ & $-8.30 \%$ & $-0.92 \%$ \\
\hline GasDis & $-8.90 \%$ & $-9.32 \%$ & $-3.56 \%$ \\
\hline WaterDis & $-5.95 \%$ & $-6.11 \%$ & $-2.89 \%$ \\
\hline Construction & $-2.76 \%$ & $-2.65 \%$ & $-0.48 \%$ \\
\hline TransComm & $-2.43 \%$ & $-2.29 \%$ & $-0.51 \%$ \\
\hline OthServices & $-1.83 \%$ & $-1.76 \%$ & $-1.15 \%$ \\
\hline
\end{tabular}

In the Middle East and North Africa, we can see that the industries most vulnerable to reductions in water availability are found in Agriculture, with the addition of Extraction and Manufacturing. However, when water is reallocated on the basis of economic returns, agricultural productions like rice, wheat, oil seeds and others are significantly cut down, whereas the production of textiles and manufactured goods is expanded.

Using terminology from international trade theory, we can say that MENA gets a comparative disadvantage in water-intensive industries, when water gets scarce and affects productivity. In other words, it is not economically efficient to produce water intensive crops like rice or oil seeds, as long as they can be safely imported and paid with exports (e.g., light manufacturing), having a lower impact on water resources.

Another way to highlight the same effect is through the virtual water concept. Since water is needed for the production of goods and services, the water employed is virtually exported as "embodied" into the traded goods. Analogously, importing goods (and services) requiring water in their production processes can be interpreted as virtual water imports.

Since we have data on water utilized in all industries and regions, we can readily estimate regional "virtual water trade balances". A virtual water trade deficit can be interpreted as saved (domestic) water resources, because of trade exchanges with the rest of the world. Furthermore, we can assess whether and how much the virtual water balance varies in the three simulation scenarios, when water 
consumption is reduced in some regions. The variations in the virtual water trade balances are displayed in Table 6.

Table 6

Variations in virtual water trade balances

(Millions $\mathrm{m}^{3}$ )

\begin{tabular}{|l|r|r|r|}
\hline & \multicolumn{1}{|c|}{ NRUS } & \multicolumn{1}{c|}{ DRUS } & \multicolumn{1}{c|}{ DRES } \\
\hline N_America & 5657 & 4365 & 6951 \\
\hline C_America & 1329 & 1213 & 1479 \\
\hline S_America & 2292 & 1911 & 3877 \\
\hline W_Europe & 3306 & 2996 & 3687 \\
\hline E_Europe & 4491 & 4295 & 8116 \\
\hline MENA & -23393 & -24764 & -40979 \\
\hline Sahel & 150 & 54 & 292 \\
\hline C_Africa & -93 & -212 & 192 \\
\hline S_Africa & 1086 & 1002 & 1547 \\
\hline C_Asia & 407 & 265 & 980 \\
\hline E_Asia & 2907 & 6117 & 6046 \\
\hline S_Asia & -3116 & -1410 & 795 \\
\hline SE_Asia & 3924 & 3420 & 5024 \\
\hline Australasia & 1052 & 747 & 1993 \\
\hline
\end{tabular}

Our results suggest that international trade is an important mechanism to alleviate the economic consequences of water scarcity, especially for the MENA. However, there is no simple and direct relationship between virtual water trade and water availability. This is because virtual water trade reflects real trade in tangible goods, especially agricultural products, and the structure of international trade is actually affected by several factors, not just the degree of access to natural resources.

\section{Discussion}

TBW

\section{Conclusion}

TBW

\section{References}

Becker N., Lavee D. and D. Katz (2010), "Desalination and Alternative Water-Shortage Mitigation Options in Israel: A Comparative Cost Analysis”, J. Water Resource and Protection, vol. 2, pp. 10421056. 
Kriegler E., B.C. O’Neill, S. Hallegatte, T. Kram, R.J. Lempert, R.H. Moss and T. Wilbanks (2012), "The need for and use of socio-economic scenarios for climate change analysis: A new approach based on shared socio-economic pathways”, Global Environmental Change, vol. 22, pp. 807-822.

Moolman C. E., J. N. Blignaut and R. van Eyden (2006), "Modelling the marginal revenue of water in selected agricultural commodities: A panel data approach”, Agrekon, vol. 45(1), pp. 78-88.

O’Neill B.C., E. Kriegler, K. Riahi, K.L. Ebi, S. Hallegatte, T.R. Carter, R. Mathur and D.P. van Vuuren (2014), “A new scenario framework for climate change research: the concept of shared socio-economic pathways”, Climatic Change, vol. 122, pp. 387-400.

Roson R. (2016), Simulating the Macroeconomic Impact of Future Water Scarcity, Water Global Practice Discussion Papers, The World Bank, Washington D.C.

Roson R., Damania R. (2016), Simulating the Macroeconomic Impact of Future Water Scarcity: an Assessment of Alternative Scenarios, IEFE Working Paper n.84/2016. Ca'Foscari DEC Working Paper n.07/2016.

WRG, The 2030 Water Resources Group (2009), Charting Our Water Future: Economic frameworks to inform decision-making. 


\section{Appendix A - An assessment of future water deficits}

The assessment of future water deficits is based on a limited set of SSP forecasts of income and population growth, complemented by CGE simulations aimed at enlarging the number of estimated economic variables. The exercise is conducted for two years, 2050 and 2100, and for two SSPs: SSP1, termed "Sustainability", and SSP3, termed "Regional Rivalry". For each combination of year and SSP, growth rates in population and GDP have been assumed, using data from the IIASA SSP repository. By shocking the corresponding parameters in the GTAP CGE model (dataset 9.0), several other endogenous variables were obtained, like production volumes by industry and region, household consumption, regional investments, exports and imports, income by source, etc.

Estimates of industrial output are especially relevant here because, coupled with our calculated water intensity coefficients (Roson and Damania, 2016), allowed us to derive the implied water demand for the years 2050 and 2100. Analogously, municipal water demand was computed by assuming it dependent on population growth, real income levels and a trend of increased water efficiency. Table A1 presents the water demand projections for the four cases (SSP1 and SSP3, 2050 and 2100). The rest of the paper, however, focuses on the SSP1/2050 case only.

Regional water deficits are defined as the difference between potential water demand and sustainable water supply. In turn, the latter is identified as the sum of water runoff and inflow in a region, estimated by the global hydrologic GCAM model ${ }^{1}$, driven by three different Global Circulation Models (CCSM, GISS, FIO ESM). We found that four macro-regions have levels of potential SSP1 demand exceeding sustainable supply in the year 2050, as showed in Table 1 of this paper.

\footnotetext{
${ }^{1}$ http://www.globalchange.umd.edu/models/gcam
} 
Table A1

Water demand projections (potential demand consistent with SSP scenarios)

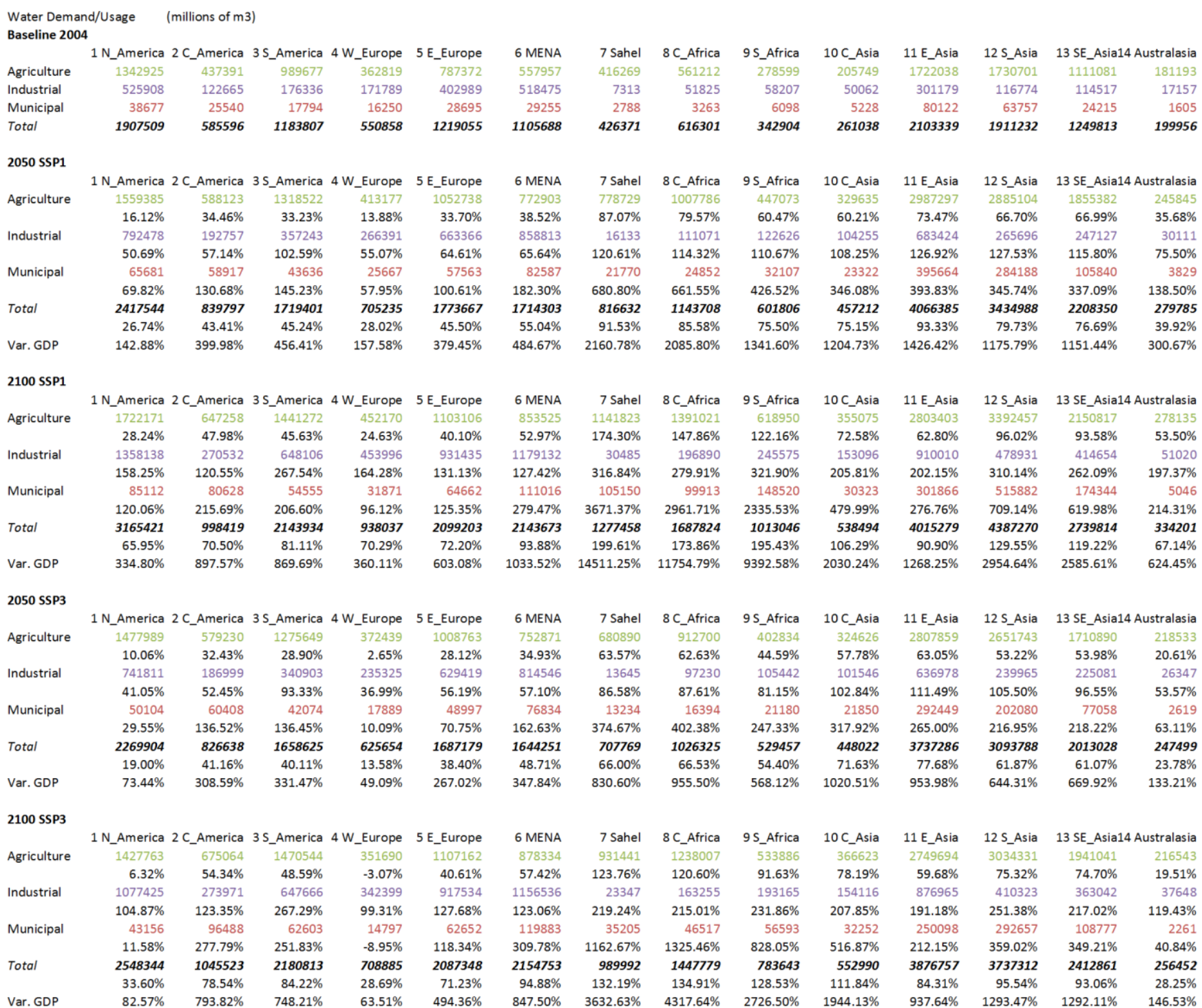




\section{Appendix B - Estimation of the marginal value and output elasticity of water}

When water is regarded as a production factor, the Marginal Value of Water (MVW) is the increase in the value of output potentially obtainable when one unit of water (here, one square meter) is added to the process, while keeping all the other production factors unchanged. The concept is strictly linked to that of water pricing and allocation: (a) profit maximization and cost minimization imply that MVW should equate the price of water; (b) water (or any other resource) is efficiently allocated (from an economic viewpoint) when its marginal value is the same across alternative uses.

In principle, estimating the MVW would require specific technical information on the production processes and how water contributes to them. This is simply impossible to get for large aggregate sectors and regions. Instead, we propose here a methodology for a consistent estimation of MVW in 15 industries and 14 macro-regions, based on available "water intensity coefficients" (WIC - water per value of output) and two calibrated parameters. WIC (indicated in the following as $\omega$ ) and MVW are related but distinct concepts. Mathematically, WIC is just the ratio of water over output (in value terms), whereas MVW is the partial derivative of output value with respect to water.

The estimation procedure is based on a set of sensible assumptions one could impose on the water elasticity of output $(\varepsilon)$. The latter is defined as the relative (percentage) variation of output $(x)$ obtainable through a relative variation in the water input $(w)$, ceteris paribus:

$\varepsilon=\frac{\delta x / x}{\delta w / w}=\frac{\delta x}{\delta w} \frac{w}{x}=\frac{\delta x}{\delta w} \omega=M V W \omega$

Consider $\varepsilon$ to be a function of $\omega$. Obviously, one would require that $\varepsilon(0)=0$, because no variation in output would be observed if water is not used at all as a factor. A second sensible assumption is:

$\lim _{\omega \rightarrow \infty} \varepsilon(\omega)=1$

meaning that, as water becomes the only relevant factor (enormous amounts of water are employed), the output varies proportionally with water (constant returns to scale). A smooth function with the two properties above would then be characterized by $\varepsilon^{\prime}(\omega)>0$ and $\varepsilon^{\prime \prime}(\omega)<0$ : the marginal value is positive but decreasing.

One of the simplest mathematical functions that can be adopted to express $\varepsilon(\omega)$ is the powered semilogistic one:

$\varepsilon(\omega)=\left(\frac{\alpha \omega}{1+\alpha \omega}\right)^{\beta} \omega \geq 0 \beta>0$

By plugging (3) into (1), and solving for the MVW, a relationship linking MVW to WIC $(\omega)$ is obtained:

$M V W=\omega^{-1}\left(\frac{\alpha \omega}{1+\alpha \omega}\right)^{\beta}$

This allows us to infer the marginal value of water on the basis of the water intensity, once the values of $a$ and $\beta$ have been set. We calibrated the values for these parameters using some estimates by Moolman, Blignaut and van Eyden (2006), who computed the MVW for five categories of fruits in 
South Africa, in the year 2002, and our own estimates of the industrial water intensity for the year 2004 (Roson and Damania, 2016). The beta parameter is calibrated by imposing that MVW equals 1.312 (simple mathematical average of the estimates by Moolman et al., cit.) when WIC $(\omega)$ is 0.01039 (our estimated value for Vegetables and Fruits in South Africa). The alpha parameter is simultaneously obtained through numerical optimization, imposing the requirement that the variance of MVW values by Moolman et al. equals the variance of MVW across South-African industries (excluding the outlier Services). The computed values are 0.637 for alpha, 0.855 for beta. Table B1 presents the corresponding MVWs.

Table B1 - Industrial MVW 2004 (US\$/M³)

\begin{tabular}{|c|c|c|c|c|c|c|c|c|c|c|c|c|c|c|}
\hline & N_America & C_America & S_America & W_Europe & E_Europe & MENA & Sahel & C_Africa & S_Africa & C_Asia & E_Asia & S_Asia & SE_Asia & Australasia \\
\hline Rice & 1.247 & 1.025 & 1.151 & 1.494 & 1.290 & 1.352 & 1.165 & 1.194 & 1.013 & 0.847 & 1.359 & 1.102 & 1.163 & 1.071 \\
\hline Wheat & 1.237 & 1.531 & 1.344 & 1.513 & 1.197 & 1.375 & 1.113 & 1.847 & 1.449 & 1.006 & 1.282 & 1.224 & 1.275 & 1.190 \\
\hline Cereals & 1.278 & 1.303 & 1.267 & 1.489 & 1.267 & 1.357 & 0.998 & 1.375 & 1.181 & 1.085 & 1.238 & 1.158 & 1.356 & 1.165 \\
\hline VegFruit & 1.372 & 1.451 & 1.199 & 1.724 & 1.508 & 1.553 & 1.327 & 1.400 & 1.312 & 1.408 & 1.683 & 1.413 & 1.258 & 1.614 \\
\hline Oilseeds & 1.495 & 1.570 & 1.582 & 1.830 & 1.299 & 1.413 & 1.064 & 1.519 & 1.236 & 0.528 & 1.423 & 1.309 & 1.915 & 1.231 \\
\hline Sugar & 1.464 & 1.282 & 1.192 & 1.781 & 1.390 & 1.474 & 1.083 & 1.670 & 1.347 & 1.181 & 1.379 & 1.321 & 1.278 & 1.286 \\
\hline Oth Crops & 1.519 & 1.490 & 1.512 & 2.149 & 1.468 & 1.708 & 1.280 & 1.403 & 1.505 & 1.634 & 2.096 & 1.927 & 1.498 & 1.568 \\
\hline Oth Agr. & 1.912 & 1.730 & 1.653 & 2.303 & 1.768 & 1.699 & 1.181 & 1.353 & 1.600 & 1.498 & 1.858 & 1.503 & 1.436 & 1.932 \\
\hline Extraction & 1.910 & 1.832 & 2.063 & 2.293 & 1.815 & 1.843 & 1.873 & 1.981 & 1.816 & 1.857 & 2.317 & 2.044 & 2.077 & 2.462 \\
\hline P.Food & 3.098 & 3.425 & 3.037 & 3.628 & 2.442 & 3.067 & 2.917 & 2.917 & 2.917 & 2.917 & 3.436 & 2.969 & 3.098 & 3.650 \\
\hline Textiles & 3.036 & 2.883 & 2.944 & 3.472 & 2.417 & 3.141 & 2.719 & 2.719 & 2.719 & 2.719 & 3.452 & 3.188 & 2.975 & 3.181 \\
\hline Light Man & 3.825 & 3.426 & 3.343 & 4.264 & 2.914 & 3.158 & 3.076 & 3.076 & 3.076 & 3.076 & 3.396 & 2.655 & 3.271 & 4.113 \\
\hline Heavy M. & 3.481 & 3.211 & 3.027 & 3.908 & 2.782 & 2.845 & 2.793 & 2.793 & 2.793 & 2.793 & 3.167 & 2.591 & 2.926 & 3.648 \\
\hline Utilities & 2.126 & 2.040 & 1.739 & 2.370 & 2.059 & 1.922 & 1.871 & 1.871 & 1.871 & 1.871 & 2.243 & 1.999 & 1.916 & 2.293 \\
\hline Services & 19.508 & 18.617 & 19.970 & 27.501 & 19.657 & 18.041 & 17.410 & 17.410 & 17.410 & 17.410 & 25.398 & 19.973 & 17.921 & 25.188 \\
\hline
\end{tabular}

Notice that, the higher the average productivity of water (value of output per $\mathrm{m}^{3}$, the inverse of the WIC), the higher the marginal value of water. In this respect, allocating water resources on the basis of the relative industrial water productivity (as it is done in the DRES scenario) is conceptually equivalent to allocating water on the basis of the relative marginal values.

The output elasticity of water is the percentage increase in gross production volumes obtained through higher water utilization. If no adjustment takes place in the production processes and in the use of other factors, then the elasticity is just the product of MVW and WIC. To get more meaningful effects when water availability is varied, we allow in this study some implicit adjustment in complementary factors, by expressing the output elasticity of water $(\eta)$ as a linear function of the product $(\varepsilon)$ : 
where the $\gamma$ and $\delta$ parameter values are set so that the average elasticity is 0.8 and the standard deviation is 0.2. Table B2 shows the elasticities obtained in this way.

Table B2 - Industrial output elasticity of water

\begin{tabular}{|c|c|c|c|c|c|c|c|c|c|c|c|c|c|c|}
\hline & N_Amer & C_Amer & S_Amer & W_Euro & E_Europe & MENA & Sahel & C_Africa & S_Africa & C_Asia & E_Asia & S_Asia & SE_Asia & Austral \\
\hline Rice & 0.9292 & 1.3853 & 1.0672 & 0.7654 & 0.8851 & 0.8360 & 1.0426 & 0.9968 & 1.4232 & 2.2836 & 0.8316 & 1.1668 & 1.0468 & 1.2464 \\
\hline Wheat & 0.9397 & 0.7534 & 0.8415 & 0.7593 & 0.9933 & 0.8211 & 1.1435 & 0.7009 & 0.7833 & 1.4489 & 0.8925 & 0.9562 & 0.8995 & 1.0026 \\
\hline Cereals & 0.8958 & 0.8737 & 0.9067 & 0.7672 & 0.9068 & 0.8325 & 1.4817 & 0.8215 & 1.0160 & 1.2093 & 0.9392 & 1.0540 & 0.8331 & 1.0428 \\
\hline VegFruit & 0.8233 & 0.7822 & 0.9902 & 0.7140 & 0.7609 & 0.7474 & 0.8540 & 0.8070 & 0.8657 & 0.8028 & 0.7201 & 0.7998 & 0.9166 & 0.7326 \\
\hline Oilseeds & 0.7653 & 0.7429 & 0.7398 & 0.7024 & 0.8768 & 0.8001 & 1.2655 & 0.7572 & 0.9419 & 1.6063 & 0.7950 & 0.8686 & 0.6958 & 0.9469 \\
\hline Sugar & 0.7769 & 0.8922 & 0.9996 & 0.7072 & 0.8123 & 0.7730 & 1.2149 & 0.7221 & 0.8396 & 1.0168 & 0.8191 & 0.8589 & 0.8963 & 0.8886 \\
\hline OthCrop & 0.7572 & 0.7670 & 0.7595 & 0.6853 & 0.7752 & 0.7163 & 0.8939 & 0.8055 & 0.7617 & 0.7287 & 0.6870 & 0.6951 & 0.7641 & 0.7433 \\
\hline Oth Agr. & 0.6961 & 0.7132 & 0.7251 & 0.6816 & 0.7087 & 0.7176 & 1.0160 & 0.8352 & 0.7357 & 0.7641 & 0.7000 & 0.7624 & 0.7887 & 0.6948 \\
\hline Extr & 0.6962 & 0.7022 & 0.6883 & 0.6818 & 0.7037 & 0.7012 & 0.6988 & 0.6920 & 0.7037 & 0.7001 & 0.6814 & 0.6890 & 0.6877 & 0.6793 \\
\hline P.Food & 0.6757 & 0.6751 & 0.6758 & 0.6749 & 0.6795 & 0.6757 & 0.6762 & 0.6762 & 0.6762 & 0.6762 & 0.6751 & 0.6760 & 0.6757 & 0.6749 \\
\hline Textiles & 0.6758 & 0.6763 & 0.6761 & 0.6750 & 0.6799 & 0.6756 & 0.6771 & 0.6771 & 0.6771 & 0.6771 & 0.6751 & 0.6755 & 0.6760 & 0.6755 \\
\hline Light M & 0.6748 & 0.6751 & 0.6752 & 0.6746 & 0.6762 & 0.6755 & 0.6757 & 0.6757 & 0.6757 & 0.6757 & 0.6751 & 0.6775 & 0.6753 & 0.6746 \\
\hline Heavy M & 0.6750 & 0.6754 & 0.6758 & 0.6747 & 0.6768 & 0.6765 & 0.6767 & 0.6767 & 0.6767 & 0.6767 & 0.6755 & 0.6780 & 0.6762 & 0.6749 \\
\hline Utilities & 0.6860 & 0.6892 & 0.7122 & 0.6805 & 0.6884 & 0.6954 & 0.6990 & 0.6990 & 0.6990 & 0.6990 & 0.6829 & 0.6911 & 0.6958 & 0.6818 \\
\hline Constr & 0.0000 & 0.0000 & 0.0000 & 0.0000 & 0.0000 & 0.0000 & 0.0000 & 0.0000 & 0.0000 & 0.0000 & 0.0000 & 0.0000 & 0.0000 & 0.0000 \\
\hline TraspCo & 0.0000 & 0.0000 & 0.0000 & 0.0000 & 0.0000 & 0.0000 & 0.0000 & 0.0000 & 0.0000 & 0.0000 & 0.0000 & 0.0000 & 0.0000 & 0.0000 \\
\hline Serv & 0.0000 & 0.0000 & 0.0000 & 0.0000 & 0.0000 & 0.0000 & 0.0000 & 0.0000 & 0.0000 & 0.0000 & 0.0000 & 0.0000 & 0.0000 & 0.0000 \\
\hline
\end{tabular}




\section{Appendix C - The construction of regionally differentiated impact scenarios}

Simulations under the DRES and DRUS scenarios are based on the assumptions that regions, in which potential demand for water exceeds sustainable supply, differ in their capability of absorbing the excess demand (water deficit). The absorption percentages applied in the various cases are based on a mixed qualitative-quantitative analysis of the relevant characteristics, where we keep distinct the potential of technological innovation from the degree of flexibility in the economic structure and trade flows.

Looking first at the innovation side, notice that a number of technologies and management options can be put in place to improve the water efficiency (lowering demand) and/or expanding the water supply, in case of water deficit. Ideally, the different options could be ranked in terms of economic efficiency, from the lowest to the highest unit cost, and those whose unit cost (possibly including externalities) falls below the shadow value of water (increasing as the water gets scarcer) should be selected (WRG, 2009). In practice, however, the technological response to the water stress is much more complicated, as a variety of factors (technical, political, institutional, safety, etc.) ultimately affects the choice among the different technology options (Becker, Lavee and Katz, 2010).

We therefore rely on a qualitative index of technology potential for each of the potentially water stressed macro-regions, based on a subjective evaluation of several options and characteristics. Because of the subjective and qualitative nature of this index, the latter should be interpreted as expressing an informed scenario, rather than as a solid scientific appraisal of (future) technical capability in the regions.

We consider three important classes of technology or management options:

1. Desalination

2. Enhanced irrigation techniques and reduced evaporation

3. Water reuse

For each of them, we identify five "facilitating factors", possibly making the implementation of each option more likely:

1. Physical conditions (e.g., desalination projects will be more effective if most of the urban centres are found along the coast)

2. Factor availability (e.g., access to energy sources for desalination)

3. Institutional capacity (efficient level of government, quality of public institutions)

4. Human and physical capital (relevant for large and complex projects)

5. Demand potential (e.g., enhanced irrigation is primarily targeted to agriculture, therefore its effectiveness depends on the share of agricultural water on total water consumption)

We assign to each factor in each region and for all the three alternatives above a simple scoring system: 1 (poor), 2 (average), 3 (good). A “Technology Potential Index" (Table C1) is quite naturally obtained by simply adding up all the given points. The higher this index, the easier is the expected capability of a region to adjust to water deficits through the introduction of new technologies and more efficient management techniques. 
Table C1 - Regional Technology Potential Index

\begin{tabular}{|r|r|r|r|r|}
\hline MENA & Sahel & C_Asia & E_Asia & S_Asia \\
\hline 31 & 28 & 30 & 35 & 31 \\
\hline
\end{tabular}

A second adjustment mechanism is related to the endogenous changes in the regional economic structure. Indeed, when actual water availability turns out to be lower than what would be required for production and consumption purposes, the consumers' utility diminishes and the productivity in waterusing industries declines. Even in the absence of a formal market for water resources, scarcity is transmitted as a price signal, and a structural adjustment takes place in the economic system, alleviating the overall impact of the negative shock for the economy. What is maybe less known is that the same process leads to an improvement in the aggregate water efficiency or productivity (water per unit of output), whose magnitude - however - depends on a series of specific characteristics of the economic system under consideration.

Many factors contribute in determining the structural flexibility, and it is not easy to ascertain what economies could respond better and why. To shed some light on this issue, we performed a simple numerical experiment with the global general equilibrium model. In each of the potentially water stressed macro-regions, we simulated a $-10 \%$ reduction in multi-factor productivity in agriculture, which is the sector where most of the water is utilized. The consequent drop in total agricultural output volume is shown in Table C2.

Table C2 - Agricultural output change

\begin{tabular}{|l|r|}
\hline Region & Var. \\
\hline MENA & $-8.71 \%$ \\
\hline Sahel & $-7.80 \%$ \\
\hline Central Asia & $-12.20 \%$ \\
\hline East Asia & $-4.22 \%$ \\
\hline South Asia & $-5.15 \%$ \\
\hline
\end{tabular}

A CGE model cannot capture all the factors and characteristics affecting the actual degree of flexibility in a certain economy. Nonetheless, a simple experiment like the one above can offer an order of magnitude, or at least can suggest a ranking of the regional economies from the most rigid one (Central Asia) to the most flexible one (East Asia), in terms of absorption of productivity shocks in agriculture, possibly induced by water scarcity.

We combine the ranking provided by Tables C1 and C2 to split the absorption of the excess water demand in the three components: internal structural adjustment, technical and management solutions, and reduction in water delivery. The latter component, which is obtained as a residual, determines the amount of decrease in water delivery (with effects on productivity) in the scenarios DRUS and DRES. 
Table C3 - Decomposition of excess water demand absorption

\begin{tabular}{|l||r|r|r|r|r|}
\hline & MENA & Sahel & C_Asia & E_Asia & S_Asia \\
\hline Internal alloc. & 0.42 & 0.44 & 0.36 & 0.52 & 0.5 \\
\hline Tech solutions & 0.32 & 0.26 & 0.3 & 0.4 & 0.32 \\
\hline Water cuts & 0.26 & 0.3 & 0.34 & 0.08 & 0.18 \\
\hline
\end{tabular}

